\title{
Analysis and Compensation of PCC Voltage Variations caused by Wind Turbine Power Fluctuations
}

\author{
Ji-Hoon Im*, Seung-Ho Song ${ }^{\dagger}$, and San Kang ${ }^{* *}$ \\ ${ }^{* \dagger}$ Dept. of Electrical Engineering, Kwangwoon University, Seoul, Korea \\ ${ }^{* *}$ KACO New Energy Inc., Sungnam, Korea
}

\begin{abstract}
The voltage variation problem at the point of common coupling (PCC) in a grid-connected wind turbine is investigated. The voltage variation problem is one of the most frequent power quality issues for the grid connection of large amounts of input power in a weak grid. Through the simplified modeling of the wind turbine and power network, the magnitude of PCC voltage variation is calculated by using the equivalent circuit parameters and output power of the wind turbine. The required amount of reactive power that can compensate the voltage variation is also presented analytically by using the vector diagram method. The proposed calculation and compensation method of the PCC voltage variation is verified by computer simulations and experiments.
\end{abstract}

Key words: Grid connection, PCC voltage variation, Power fluctuation, Reactive power compensation

\section{INTRODUCTION}

The installation capacity of wind turbine systems has been rapidly increasing around the world. For instance, more than 20 percent of the annual electricity consumption of Denmark comes from wind energy. More challenging target ratios are also being set in Europe, United States, and Asia. [1] The power quality issues accompanying the integration of fluctuating wind turbine sources should be solved to accommodate large amounts of energy into existing power system networks. [2]

Wind turbine systems belong to a distributed generation system because they are usually positioned at diverse locations and have relatively small sizes. By contrast, conventional power generation plants, such as coal, gas, and nuclear plants, are called central power generation stations. Output power quality, such as voltage and frequency, are strictly regulated by the generation control system in conventional power stations. However, the output voltage of the wind turbine system can fluctuate because of variable wind energy input and the

Manuscript received Aug. 22, 2012; revised May 28, 2013

Recommended for publication by Associate Editor Kyeon Hur.

${ }^{\dagger}$ Corresponding Author: ssh@kw.ac.kr

Tel: +82-940-5762, Fax: +82-943-7195, Kwangwoon University

*Dept. of Electrical Engineering., Kwangwoon University, Korea

${ }^{* *}$ KACO New Energy Inc., Korea impedance of the connecting line between the point of common coupling (PCC) and power network. This type of voltage variation is one of the most significant power quality problems. Any excessive increase in grid voltage can cause damage to neighboring electric devices.

The technical problem of the voltage variation at the connection point can be solved if a new and exclusive line is built for the transmission of power from wind energy. However, we want to use the existing power network for wind power integration because a new line installation is costly in terms of time and financial resources.

Analyzing and compensating precisely the voltage variation at the PCC are important in wind turbine integration. Some conventional compensation methods on voltage variation use the injection of the reactive power as a feedback control loop by sensing directly the PCC voltage. [2] However, measuring the $\mathrm{PCC}$ voltage precisely is difficult because the sensing point is usually located outside the power converter unit. The measured voltage can be contaminated during high-speed inverter switching. The compensating reactive power reference is sometimes easily saturated because the voltage variation at the PCC cannot be regulated by a local unit with a relatively small size. The appropriate sizing of reactive power compensation devices requires the analytic model of the voltage variation at the $\mathrm{PCC}$ voltage. 


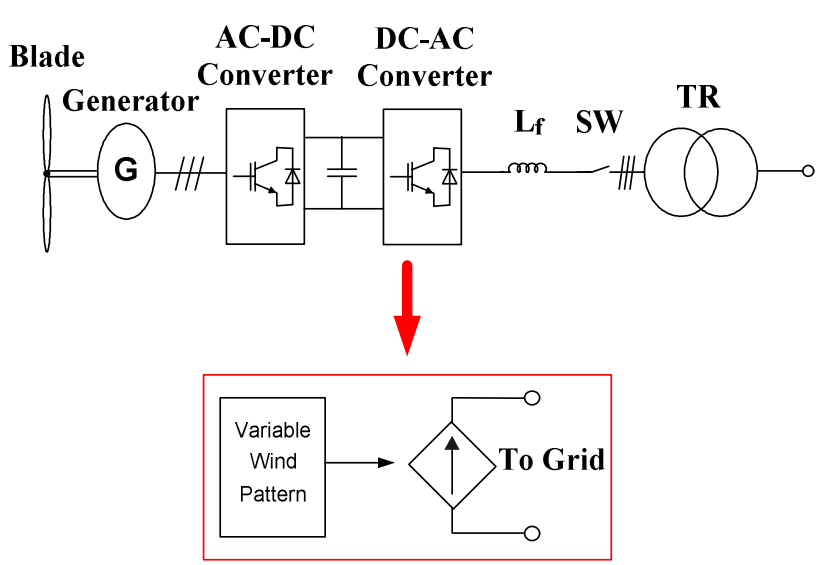

Fig. 1. Simplified model of the grid-connected inverter of a wind turbine.

In this paper, a new compensation method is proposed for the voltage variation at the PCC due to the output power fluctuations from the wind. By using the analytic modeling in [3] and the vector diagram analysis of the voltage variation at the PCC, we can calculate the required amount of reactive current for the compensation with a variable margin of voltage variation. A nonlinear graph of the required reactive power is shown against the change of the active power output with a different value of voltage variation margin. Simulations and experimental results are compared to verify the feasibility of the proposed method.

\section{ANALYSIS OF VOLTAGE VARIATIONS CAUSED BY THE WIND TURBINE}

\section{A. Wind Turbine Modeling}

Wind turbine systems generally have a generator, grid-connected inverter, filter, and transformer. Energy from the blades is outputted by the grid-connected inverter through a DC-link capacitor.

Fig. 1 shows that the wind turbine can be modeled as a controllable current source with variable wind speeds if the inverter performs the current control successfully with power factor control function.

\section{B. Voltage Variation Analysis}

Regardless of the complexity of an actual power system network, the equivalent $\mathrm{T}$-shaped circuit diagram can be derived at the PCC for the simple calculations of voltage deviations due to input power fluctuations. Fig. 2 shows that the T-equivalent circuit has three branches: conventional voltage source, current source of input power, and system loads. The parameters in Table I are actual parameters in Sapsi Island and the equivalent impedances in generator voltage level for the T-equivalent circuit.

Fig. 3(a) shows the $10 \mathrm{~kW}$ wind turbine installed on Sapsi

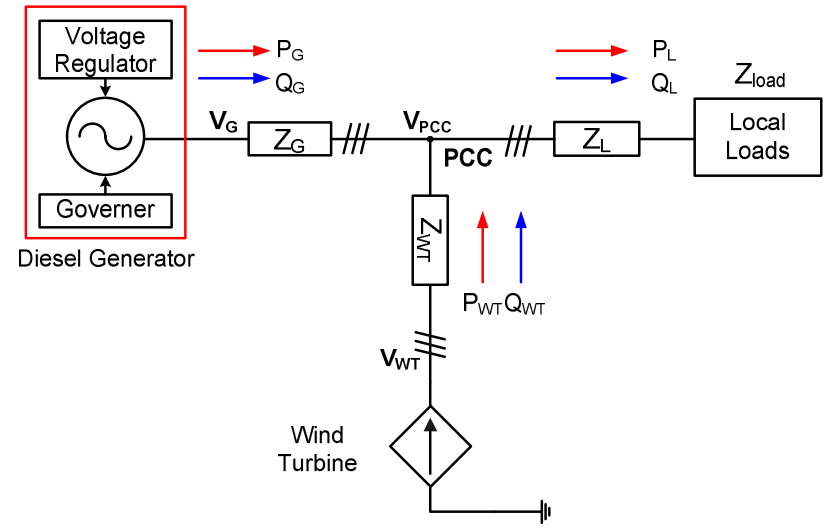

Fig. 2. T-equivalent circuit model for the analysis of voltage variations.

\section{TABLE I}

IMPEDANCES FOR THE T-EQUIVALENT CIRCUIT MODEL

\begin{tabular}{|c|c|c|}
\hline Symbol & Descriptions & Value \\
\hline $\mathbf{V}_{\mathbf{G}}$ & $\begin{array}{c}\text { Regulated voltage source } \\
\text { / Base voltage }\end{array}$ & $380[\mathrm{~V}]$ \\
\hline $\mathbf{Z}_{\mathbf{G}}$ & $\begin{array}{c}\text { Equivalent line impedance at PCC } \\
\text { to the diesel generator }\end{array}$ & $\begin{array}{c}0.625<72.37 \\
{[\Omega]}\end{array}$ \\
\hline $\mathbf{Z}_{\mathbf{L L}}$ & $\begin{array}{c}\text { Equivalent load impedance at PCC } \\
\text { including the line impedance for } \\
\text { the load connection }\end{array}$ & $\begin{array}{c}4.19<22.24 \\
{[\Omega]}\end{array}$ \\
\hline $\mathbf{Z}_{\mathbf{W T}}$ & $\begin{array}{c}\text { Equivalent impedance at PCC for } \\
\text { the connection of wind turbine }\end{array}$ & $\begin{array}{c}0.085<5.05 \\
{[\Omega]}\end{array}$ \\
\hline
\end{tabular}

Island, Korea. Fig. 3(b) shows the measured PCC voltage data against the output power of the wind turbine. The sampling frequency is $1 \mathrm{~Hz}$. The center line represents the calculated PCC voltage. The dotted lines show the variation margin caused by the voltage regulation error recognized during the zero output power generation.

$$
\mathbf{Z}_{\mathbf{L L}}=\mathbf{Z}_{\mathbf{L}}+\mathbf{Z}_{\text {load }}
$$

Where

$Z_{L} \quad$ : Equivalent line impedance between $Z_{\text {load }}$ and PCC

$Z_{\text {load }}$ : Equivalent impedence of load

$$
\mathbf{V}_{\mathbf{P C C} \mathbf{0}}=\left(\frac{\mathbf{Z}_{\mathbf{L L}}}{\mathbf{Z}_{\mathbf{L L}}+\mathbf{Z}_{\mathbf{G}}}\right) \mathbf{V}_{\mathbf{G}}=V_{p c c 0} \angle 0
$$

Where

$\mathrm{V}_{\mathrm{PCC} 0}$ : PCC voltage at no WT output

$V_{G}:$ Terminal voltage of the grid

$$
\mathbf{I}_{\mathbf{W T}}=I_{W T} \angle 0
$$

Where

$I_{w T}$ : Output active current of wind turbine

$$
\mathbf{Z}_{\text {effect }} \equiv \frac{\mathbf{Z}_{\mathbf{G}} \cdot \mathbf{Z}_{\mathbf{L L}}}{\mathbf{Z}_{\mathbf{L L}}+\mathbf{Z}_{\mathbf{G}}}=Z_{\text {effect }} \angle \theta
$$




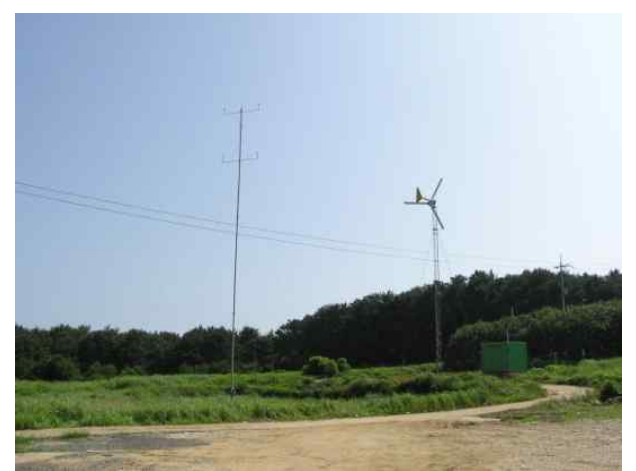

(a)

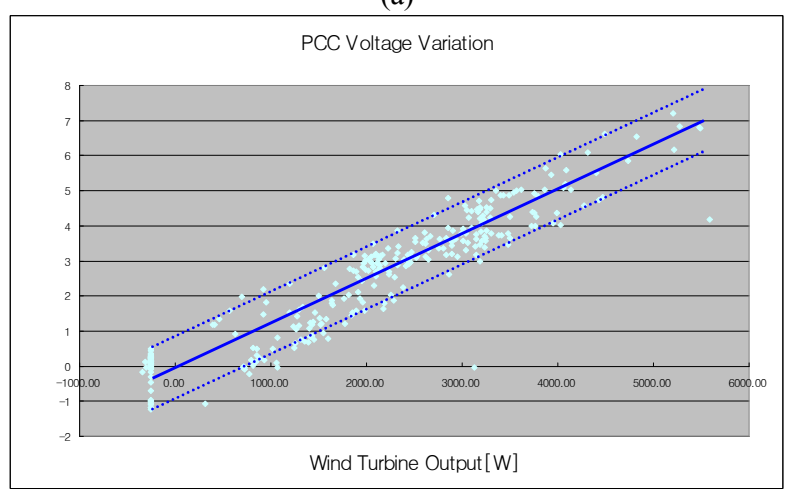

(b)

Fig. 3. A wind turbine installed on Sapsi Island. (a) A $10 \mathrm{~kW}$ wind turbine on Sapsi Island. (b) Measured voltage at the PCC against the wind turbine output power.

$$
\begin{aligned}
& \begin{array}{l}
\text { Where } \\
\mathbf{Z}_{\mathbf{G}}: \text { Equivalent line impedance between internal } \\
\text { combustion power plant and PCC }
\end{array} \\
& \qquad \mathbf{V}_{\mathbf{P C C}}=\mathbf{V}_{\mathbf{P C C} 0}+\mathbf{Z}_{\text {effect }} \mathbf{I}_{\mathbf{W T}} \\
& \qquad V_{P C C}=\left|\mathbf{V}_{\mathbf{P C C}}\right|-\left|\mathbf{V}_{\mathbf{P C C 0}}\right| \\
& =\sqrt{V_{p c c 0}^{2}+2 V_{p c c 0} Z_{e f f e c t} I_{W T} \cos \theta+\left(Z_{\text {effect }} I_{W T}\right)^{2}}-V_{p c c 0}, \\
& \text { Where } \\
& \Delta V_{P C C}: \mathbf{R M S} \text { amplitude of voltage variation at PCC }
\end{aligned}
$$

The equivalent load impedance in (1) includes the load and line impedances for the load connection. The PCC voltage without power connection is expressed in (2). The current vector of the wind turbine is assumed aligned with the phase angle of $\mathbf{V}_{\mathbf{P C C} \mathbf{0}}$, which is achieved in many grid-connected inverters by the unity power factor control function in (3). We define the parallel impedance of the equivalent line impedance, $\mathbf{Z}_{\mathbf{G}}$, and the equivalent load impedance, $\mathbf{Z}_{\mathbf{L L}}$, as the effective impedance, $\mathbf{Z}_{\text {effect }}$, in (4). The angle of the voltage deviation vector is determined by the effective impedance, $\mathbf{Z}_{\text {effect }}$ (Fig. 4). The voltage deviation at the PCC is analytically expressed as the effective line impedance at the PCC multiplied by the current from the wind turbine in (5). Note that the value of the impedance of the connecting cable between the PCC and wind turbine has no effect on the voltage at the PCC because the wind turbine is modeled as a current source. For the low voltage-side connection of the wind turbine, the voltage deviation at the PCC can be a significant problem because the other local loads can be connected to the PCC and because effective line impedance becomes high due to the impedance of the grid-connected transformer.

The phasor vector diagram analysis is used to calculate the amount of voltage variation $\Delta \mathrm{V}_{\mathrm{PCC}}$ (Fig. 4). Thus, the amount of voltage variation can be calculated $\left|\mathbf{V}_{\text {PCC }}\right|-\left|\mathbf{V}_{\text {PCC } 0}\right|$ by subtracting the magnitude of $\mathbf{V}_{\text {PCC0 }}$ from the magnitude of $\mathbf{V}_{\text {PCC }}$ in (6). The magnitude of $\mathbf{V}_{\text {PCC }}$ varies with varying $\mathbf{Z}_{\text {effect }}$ phase angles even though the size of $\mathbf{Z}_{\text {effect }}$ and $\mathbf{I}_{\mathbf{w t}}$ is the same. The resultant voltage vector, $\mathbf{V}_{\mathbf{P C C}}$, is changed from the original $\mathbf{V}_{\text {PCC0 }}$ both in magnitude and angle.

In Fig. 5, the maximum value of the PCC voltage variation is plotted according to (6). In Fig. 5(a), the maximum voltage variation is almost proportional to the amplitude of the $\mathbf{Z}_{\text {effect }}$ when the output power of the turbine is fixed at $10 \mathrm{~kW}$ (see Fig. 4). If the $\mathbf{Z}_{\text {effect }}$ is fixed (see Table I), the voltage variation increases along the curve (see Fig. 5(b)) with increasing installed wind turbine rating. [6]-[7]

\section{COMPENSATION OF VOLTAGE VARIATION BY USING REACTIVE POWER}

As explained in (5) in Chapter 2, the voltage variation at the PCC is related to the output current of the wind turbine, Iwt, and equivalent impedance at the PCC, Zeffect, in Fig. 4. If the proper amount of additional reactive current, Iwt_comp, is supplied, the magnitude of the new voltage vector, Vpcc_new, can be the same as the magnitude of the original voltage vector, Vpcc0, in Fig. 6(a). The required value of the compensation current, Iwt_comp, can be obtained from (7) when both magnitudes are equal.

However, if the required reactive current is large, the output current is limited by the rated value of the inverter. Fig. 6(b) shows that a large current limit is required to compensate for the voltage variation during the rated power output. In this case, the additional amount of the current rating is $50 \%$ of the rated current. To calculate the appropriate amount of the reactive current capacity required for the voltage compensation at the PCC, (8) is developed with the variable amount of allowable voltage margin $m$ at the PCC. If the allowance of voltage variation $m$ increases, the necessary amount of reactive current and reactive power of the inverter can be calculated as in (9) and (10), respectively. 


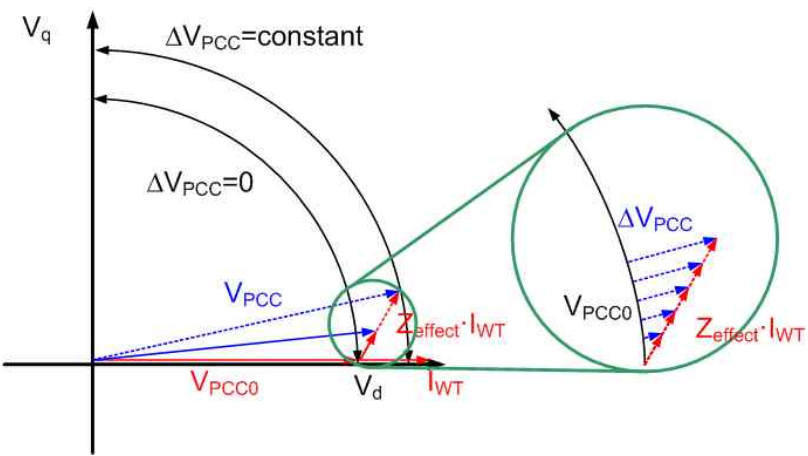

Fig. 4. Diagram of the PCC voltage variation phasor caused by the output current of the wind turbine.

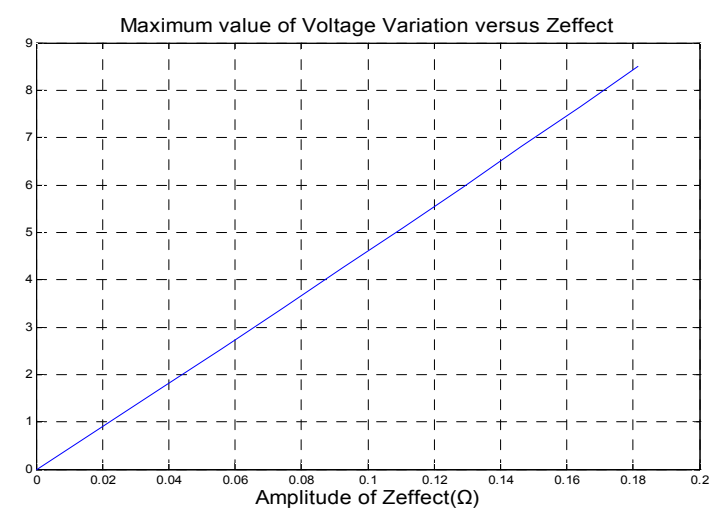

(a)

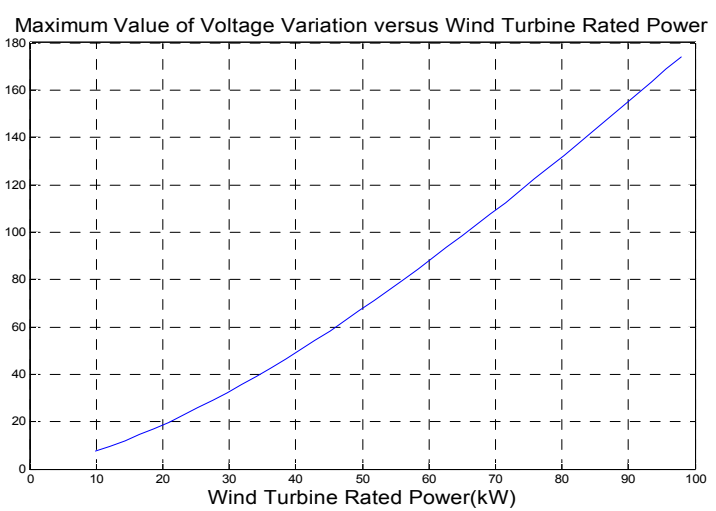

(b)

Fig. 5. Calculation of PCC voltage variation according to the wind turbine rated power and $\mathbf{Z}_{\text {effect }}$.

(a) PCC voltage variation versus $\left|\mathbf{Z}_{\text {effect }}\right|$ with constant wind turbine output power $(10 \mathrm{~kW})$.

(b) PCC voltage variation versus wind turbine rated power with constant $\mathbf{Z}_{\text {effect }}$ (Table 1) turbine output power.

Fig. 7(a) shows the block diagram for the calculation of the compensation current by using the wind turbine output current $\mathbf{I}_{\mathrm{w}}$, equivalent impedance $\mathbf{Z}_{\text {effect }}$, voltage reference at the PCC $\mathbf{V}_{\text {PCC0 }}$, and voltage margin $m$. The block diagram of the proposed reactive power and voltage allowance. Reactive current $\mathbf{I}_{\text {wt_comp }}$ is calculated by $\mathbf{I}_{\mathbf{w t}}, \mathbf{V}_{\mathbf{P C C} \mathbf{0}}$, and voltage allowance $m$. The block diagram of the proposed

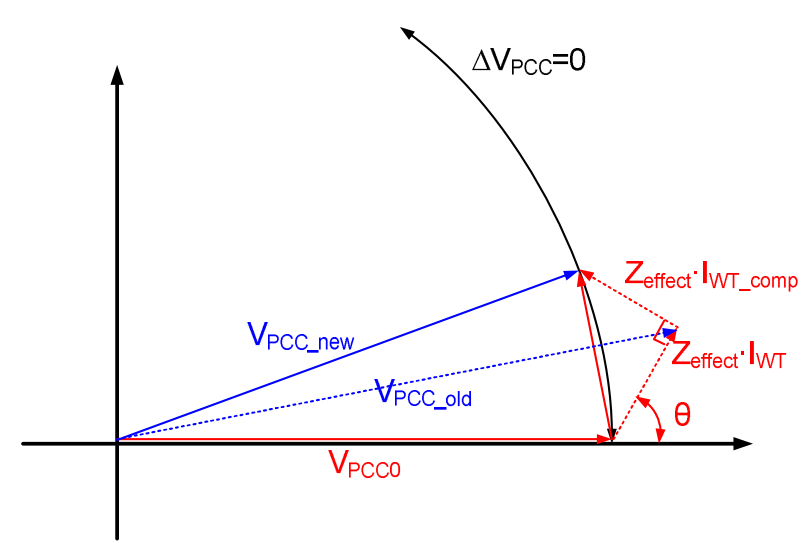

(a)

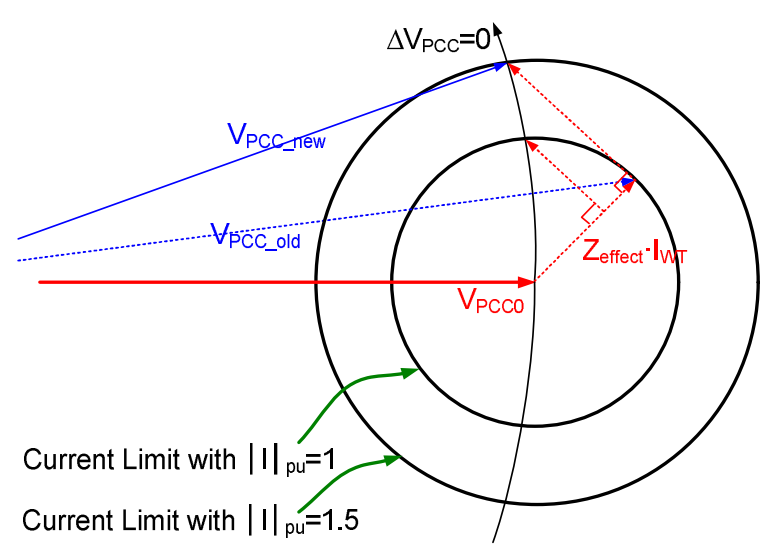

(b)

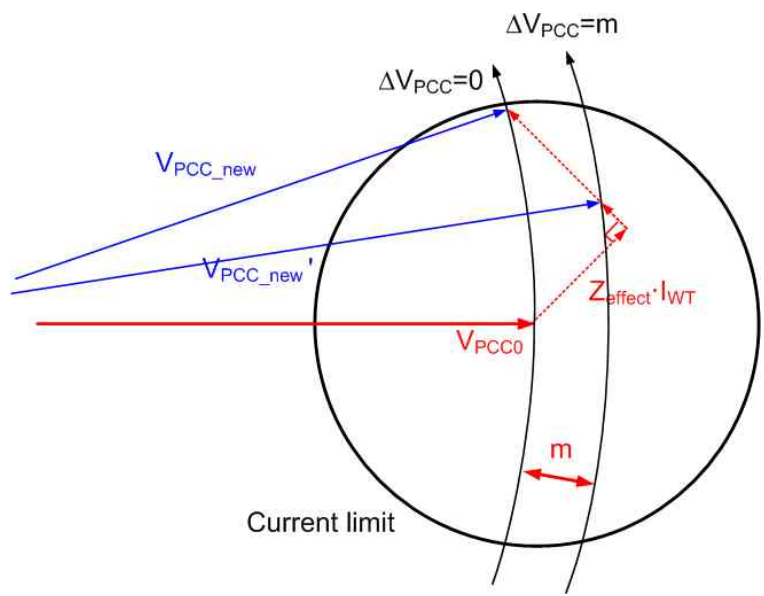

(c)

Fig. 6. Compensation of the PCC voltage variation by injection of reactive power.

(a) PCC voltage compensation phasor diagram with compensating reactive power

(b) Diagram of the PCC voltage compensation caused by the inverter capacity

(c) PCC voltage compensation phasor diagram due to the voltage variation allowance

compensation algorithm is shown in Fig. 7(b). Only the active current of the wind turbine is updated in real time for the calculation, whereas the other values are predetermined. 


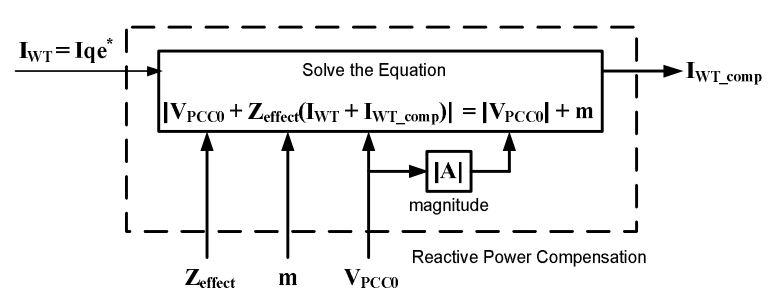

(a)

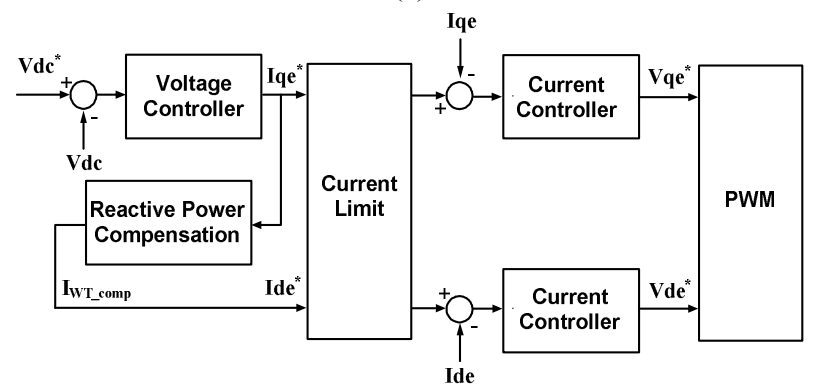

(b)

Fig. 7. Control block diagram of the proposed algorithm.

(a) Calculation of required reactive current from the active current

(b) Implementation of the proposed reactive power compensation algorithm to reduce the voltage variation at the PCC

Therefore, this algorithm is an open-loop method because it does not require the feedback of the voltage at the PCC.

However, the measurement of the initial voltage at the PCC is necessary because this measurement is used as a reference voltage in the proposed algorithm. The initial voltage is not affected by the impedance $\mathbf{Z}_{\mathbf{W T}}$ between the wind turbine and PCC because the output current of the wind turbine is zero. The reference voltage is assumed constant during the operation of the wind turbine. However, changes occur in the PCC voltage without wind power because of other power system components. This paper focuses on the reduction of the voltage variation caused by the wind turbine. A large amount of current may be required if a controller tries to compensate the voltage variation at the PCC regardless of the change in outside conditions. Therefore, the proposed algorithm compensates only the amount of contribution to the voltage variation by the wind turbine by using the network model. If an allowable voltage margin is provided, the proposed algorithm can analytically calculate the required reactive power, which is significantly reduced.

\section{Simulations AND EXPERIMENT RESUltS}

\section{A.Experimental Setup and Conditions}

Fig. 8 shows the experimental setup for the test of the proposed voltage compensation. The active power output of the inverter varies to simulate the variable wind energy input. A commercial three-phase power supply with $6 \mathrm{kVA}$ rating is used as a regulated voltage source. Other parameters

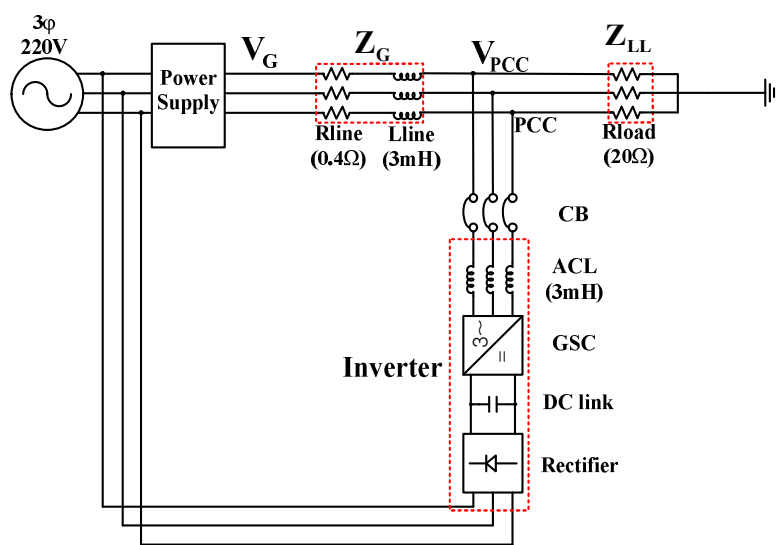

Fig. 8. Circuit composition for the experiments.

TABLE II

IMPEDANCES FOR EXPERIMENTS.

\begin{tabular}{|c|c|c|}
\hline Symbol & Descriptions & Value \\
\hline $\mathbf{V}_{\mathbf{G}}$ & Regulated voltage source & $220[\mathrm{~V}]$ \\
\hline $\mathbf{Z}_{\mathbf{G}}$ & $\begin{array}{c}\text { Equivalent line } \\
\text { impedance from the PCC to } \\
\text { the }\end{array}$ & $\begin{array}{c}1.20<70.52 \\
\text { ideal generator }\end{array}$ \\
\hline $\mathbf{Z}_{\mathbf{L L}}$ & $\begin{array}{c}\text { Equivalent load } \\
\text { impedance at the PCC } \\
\text { including the line } \\
\text { impedance for the load } \\
\text { connection }\end{array}$ & $20[\Omega]$ \\
\hline
\end{tabular}

including the voltages and impedance values for the experiments are listed in Table II

$$
\left|\mathbf{V}_{\text {PCC0 }}\right|=\left|\mathbf{V}_{\text {PCC_new }}\right|
$$

Where

$\mathrm{V}_{\text {PCC_old }}$ : PCC voltage with only active power output of WT

$\mathrm{V}_{\mathrm{PCC} \_ \text {new }}$ PCC voltage with active and reactive power output of WT

$$
\begin{aligned}
& \left|\mathbf{Z}_{\text {effect }} \mathbf{I}_{\text {WT_comp }_{1}}\right| \\
& =V_{p c c 0} \sin \theta-\sqrt{\left(V_{p c c 0}+m\right)^{2}-\left(V_{P C C 0} \cos \theta+Z_{\text {effect }} I_{W T}\right)^{2}},
\end{aligned}
$$

Where

m : Allowance range of voltage variation

$\mathbf{I}_{\mathrm{WT}_{-} \text {comp }} \quad$ : Reactive current for compensation

$$
\begin{aligned}
\mathbf{I}_{\mathbf{W T}_{\text {_comp }}}= & \mathbf{Z}_{\text {effect }} \mathbf{I}_{\mathbf{W T}_{\text {_comp }}} \div \mathbf{Z}_{\text {effect }} \\
=I_{W T_{-} \text {comp }} \angle 90^{\circ} & . \\
& \mathbf{Q}_{\mathbf{W T}}=\mathbf{V}_{\mathrm{PCC}} \times \mathbf{I}_{\mathbf{W T}_{\text {_comp }}}
\end{aligned}
$$

Where

$Q_{W T} \quad$ :Compensation reactive power 


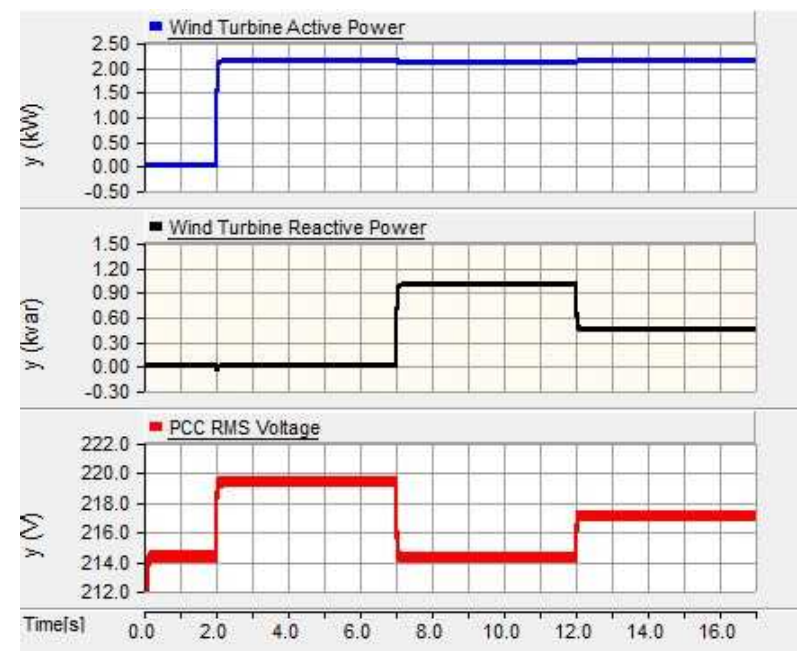

Fig. 9. Comparison of the PCC voltage with three different control strategies of the reactive power compensation by using PSCAD/EMTDC simulation.

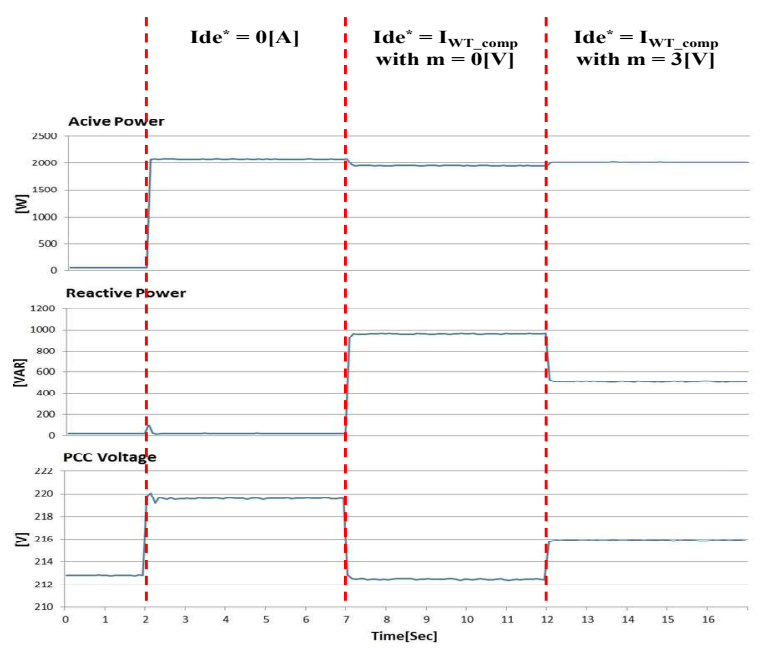

Fig. 10. Comparison of PCC voltage with three different control strategies of the reactive power compensation by using the experimental setup.

\section{B. Compensation by USING REACTIVE POWER}

Fig. 9 shows the PCC voltage variation, active power of the wind turbine, and required reactive power for the simulation model compensation. If the active power of the wind turbine increases to $2.1[\mathrm{~kW}]$, the PCC voltage variation is $6.0[\mathrm{~V}]$. In this case, the required reactive power is 1.0 [kVAR] or 0.5 [kVAR] for $0[\mathrm{~V}]$ or 3.0 [V], respectively, of the voltage variation allowance at the PCC. The required reactive power is calculated in (10) by using $\mathbf{I}_{\mathrm{wt}}, \mathbf{Z}_{\text {effect }}, \mathbf{V}_{\mathbf{P C C} \text {, }}$ and the voltage variation allowance $m$. The simulation shows that the PCC voltage variation is reduced to 0 [V] or 3.0 [V], respectively, when the calculated reactive power is injected at 7 and $12[\mathrm{~s}]$.

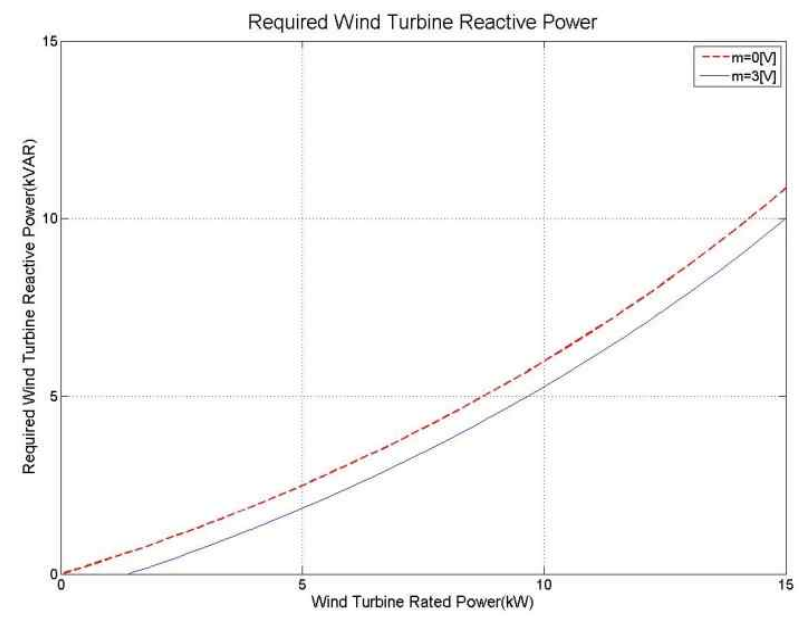

Fig. 11. Simulation results of the required maximum reactive power against the active power rating of the wind turbine with different voltage variation allowances (dashed line: voltage variation allowance, $\mathrm{m}=0[\mathrm{~V}]$, solid line: $\mathrm{m}=3[\mathrm{~V}])$.

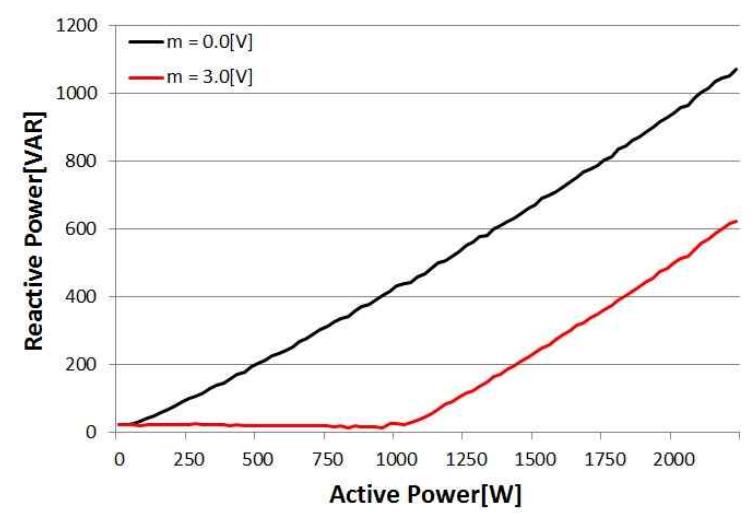

Fig. 12. Experimental results of the required maximum reactive power against the active power rating of the wind turbine with different voltage variation allowances (dashed line: voltage variation allowance, $\mathrm{m}=0[\mathrm{~V}]$, solid line: $\mathrm{m}=3[\mathrm{~V}]$ ).

Fig. 10 shows the experimental results with the same simulation scenarios and parameters in Fig. 9. In real time, the DSP controller in the inverter calculates and compensates the amount of required reactive power. The experimental results in Fig. 10 are compared with the simulation results in Fig. 9.

Fig. 11 shows the amount of required reactive power when the output of the wind turbine varies under a voltage variation allowance of either $0[\mathrm{~V}]$ or $3[\mathrm{~V}]$. The dashed and solid lines represent the required reactive power when the allowance of the voltage variation $m$ is equal to 0 and 3 [V], respectively. If the PCC voltage variation allowance is $3.0[\mathrm{~V}]$, the wind turbine does not need to inject a reactive power that is less than $1[\mathrm{~kW}]$ because the PCC voltage variation is in the allowed range. 
Fig. 12 shows the experimental results with the same simulation scenarios and parameters in Fig. 11. The range of variations of the active power is limited to $2.2[\mathrm{~kW}]$ because of the rating of the inverter in the experiments. The inverter does not need to inject a reactive power that is less than 1 [kW] of active power according to $m=3.0$ [V] in Fig. 11 .

The simulation and experiment results show that the proposed method on the programmable limit of PCC voltage variations offers significant advantages because the amount of required reactive power can be predicted and the proper size of the inverter can be designed.

\section{A. CONCLUSIONS}

This paper proposed a compensation method for the voltage variation at the PCC caused by the active power fluctuation of the grid-connected inverter for wind turbines. The amount of voltage deviation is dependent on the active power output of the wind turbine, equivalent line impedance, and load impedance. If the inverter has sufficient current rating, the voltage variation at the PCC can be completely compensated by the addition of reactive power. In actual cases, given that the inverter rating is limited, the reactive power reference is calculated by considering the allowance of the voltage variation at the PCC. Given that this proposed algorithm solves the problem created by the wind turbine, the proposed algorithm can be used to enhance power quality and improve wind energy integration.

\section{ACKNOWLEDGEMENT}

This work was supported by the Human Resources Development program (20111020400080) of the Korea Institute of Energy Technology Evaluation and Planning (KETEP) grant funded by the Korea government Ministry of Trade, Industry and Energy.

\section{REFERENCES}

[1] EWEA, "EU Energy Policy to 2050," The European Wind Energy Association, pp. 21-22, Mar. 2011.

[2] M. Triggianese, J. Morren, S.W.H. de Haan, and P. Marino, "Improved and extended DG capability in voltage regulation by reactive and active power," POWERENG2007 International Conference on Power Engineering, Energy and Electrical Drives Proceedings, pp. 583-588, Apr. 2007.

[3] J.-J. Kim and S.-H. Song, "Grid connection simulation model of variable speed wind turbine using pm synchronous generator," International Conference on Power Electronics 2004 - ECCE Asia, pp. 649 654, Oct. 2004.

[4] Kannan Rajendiran, W. W. L. Keerthipala, and C. V. Nayar "PSCAD/EMTDC based simulation of a wind-diesel conversion scheme," 2000 IEEE Power Engineering Society Winter Meeting, Vol. 1, pp. 505-510, Jan. 2000.

[5] J. T. Bialasiewicz, E. Muljadi, S. Drouilhet, and G. Nix "Modular simulation of a hybrid power system with diesel and wind turbine generation," Wind power '98 Bakersfield, Apr. 1998.

[6] J.-H. Im and S.-H. Song, "A prediction model of the voltage variation according to the wind power installation capacity in an isolated grid," IEEE $6^{\text {th }}$ International Power Electronics and Motion Control Conference 2009, pp. 1080-1084, July. 2009.

[7] J.-H. Im and S.-H. Song, "Simplified wind turbine modeling and calculation of PCC voltage variation according to grid connection conditions," The Transaction of the Korean Institute of Power Electronics, Vol. 58, No. 6, pp. 2402-2409, Dec. 2009.

[8] J.-J. Kim and S.-H. Song, "PSCAD / EMTDC simulation model of variable speed wind power generation system using permanent magnet," The Transaction of the Korean Institute of Power Electronics, Vol. 10, No. 6, pp. 610-617, Dec. 2005.

[9] S. A. Papathanassiou and F. Santjer, "Power quality measurements in an autonomous island grid with high wind penetration," IEEE Trans. Power Del., Vol. 21, No. 1, pp.218-224, Jan. 2006.

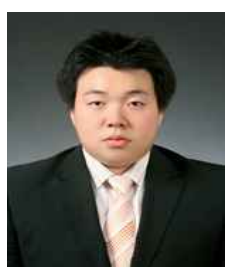

Ji-Hoon Im received his BS and MS degrees in Electrical Engineering from Korea University, Seoul, South Korea, in 2007 and 2009 , respectively. He is currently working toward a $\mathrm{PhD}$ degree at Kwangwoon University, Seoul, South Korea. His research interests include power electronics, control and renewable energy applications based on digital signal processing,

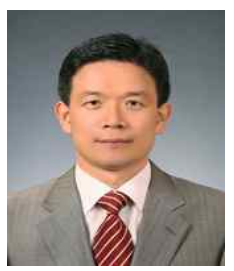

Seung-Ho Song was born in Korea in 1968. $\mathrm{He}$ received his $\mathrm{BS}, \mathrm{MS}$, and $\mathrm{PhD}$ degrees in Electrical Engineering from Seoul National University, Seoul, South Korea, in 1991, 1993, and 1999, respectively. In 1992, he joined the Pohang Iron and Steel Control Company (POSCON) as a research engineer and worked on the development of DC and AC machine drives for steel rolling mill applications until 1995. From 2000 to 2006, he was an assistant professor in the Division of Electronics and Information, Chonbuk National University, Jeonju, South Korea. He was also a visiting professor in WEMPEC, University of Wisconsin-Madison, United States, from 2004 to 2005. Since 2006, he has been a faculty member of the Department of Electrical Engineering, Kwangwoon University, Seoul, South Korea, where he is currently a full-time professor. His research interests include electric machine drives and renewable energy conversion.

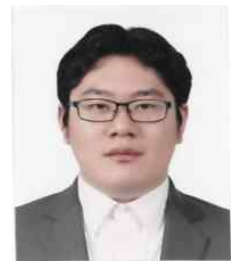

San Kang was born in Korea in 1984. He received his BS degree in Computer Software Engineering from Myungji University, Seoul, South Korea, in 2010. In 2012, he received his MS degree in Embedded Software Engineering from Kwangwoon University. $\mathrm{He}$ is currently with KACO New Energy Inc., Sungnam, South Korea. His research interests include renewable energy systems. 